\title{
Epicardial fat thickness in patients with rheumatoid arthritis
}

\author{
Erdem Fatma ${ }^{2}$, Koç Bünyamin ${ }^{1}$, Sarikaya Savas ${ }^{3}$, Uçar Mehmet ${ }^{4}$, Yazıcı Selma ${ }^{2}$, \\ Boyraz Ismail ${ }^{1}$, Caglar Sabri ${ }^{1}$, Ozyalvacli Gulzade ${ }^{5}$, Dönmez Ibrahim ${ }^{1}$, Yazici Mehmet ${ }^{1}$
}

1. Department of Cardiology, Abant Izzet Baysal University School of Medicine, Bolu, Turkey

2. Department of Cardiology, Bozok University School of Medicine Yozgat, Turkey

3. Department of Physical Medicine and Rehabilitation, Abant Izzet Baysal University School of Medicine, Bolu, Turkey

4. Department of Physical Medicine and Rehabilitation, Bozok University School of Medicine Yozgat, Turkey

5. Department of Pathology, Abant Izzet Baysal University School of Medicine, Bolu, Turkey

\begin{abstract}
Background: Epidemiologic data indicates that rheumatoid arthritis is an independent risk factor for cardiovascular disease. Epicardial adipose tissue is a novel cardio-metabolic risk factor. Our aim was to evaluate epicardial fat thickness (EFT) using echocardiography in patients with rheumatoid arthritis compared to healthy control subjects. Secondly, we investigated relationship between epicardial fat thickness and clinical and echocardiographic parameters in patients with rheumatoid arthritis. Method: The study population included 76 consecutive patients with rheumatoid arthritis ( 64 female; mean age, $53 \pm 11$ years, median disease duration, 7.8 years) and 50 healthy subjects as controls ( 39 female; mean age, $52 \pm 6$ years). All patients underwent echocardiography to assess left ventricular diastolic dysfunction, left ventricular hypertrophy and EFT. All values were compared between groups.

Results: EFT was higher in rheumatoid arthritis patients than in healthy controls $(0.66 \pm 0.20$ vs. $0.54 \pm 0.18 ; \mathrm{p}=0.003)$. Thickness of Intra Ventricular Septum (IVS) $(1.1 \pm 0.06$ and $9.8 \pm 0.08 ; \mathrm{p}=0.001)$ and posterior wall (PW) $(0.98 \pm 0.05$ and $0.93 \pm 0.08 ; \mathrm{p}=0.015)$ was higher in patients with rheumatoid arthritis compared to healthy controls. Early diastolic myocardiac peak velocity or late diastolic mitral peak velocity (E/A) ratio was lower in rheumatoid arthritis patients compared to healthy patients $(1.1 \pm 0.8$ and $1.24 \pm 0.1 \mathrm{p}=0.001)$ as well as, $\mathrm{E} / \mathrm{e}^{\prime}$ was higher in Rheumatoid arthritis $(\mathrm{RA})$ patients than healthy patients. (E/e':8.7 \pm 1.6 and $8.0 \pm 1.4 \mathrm{p}=0.020)$. In patients with rheumatoid arthritis, EFT was positively correlated with hypertension and duration of disease and E/e' (r: 0.10, p: 0.010, r: 0.306, p: 0.004 and r: 0.465 p: 0.007 respectively) and EFT was negatively correlated with E/A (r: -.262 p:0.022)

Conclusion: To our knowledge, this is the first report about epicardial adipose tissue in rheumatoid arthritis patients. Epicardial fat thickness as an indicator of cardiovascular involvement was higher in rheumatoid arthritis patients.
\end{abstract}

Keywords: Rheumatoid arthritis, epicardial fat thickness, cardiac involvement

DOI: http://dx.doi.org/10.4314/ahs.v15i2.23

\section{Introduction}

Rheumatoid arthritis (RA) is a systemic inflammatory disease characterized by chronic symmetric and erosive synovitis that preferentially affects peripheral joints, with prevalence of $0.5-1 \%$ in the population ${ }^{1}$. Epide-

\footnotetext{
Corresponding author:

Erdem Fatma,

Abant Izzet Baysal University

School of Medicine,

Department of Cardiology,

14280 Bolu, TURKEY

Telephone: +903742534616

Fax: +903742534559

E-mail:mobitztip1@gmail.com
}

miologic data indicates that RA is an independent risk factor for cardiovascular disease $(\mathrm{CVD})^{2,3}$. Emerging epidemiological evidence showed that CVDs account for approximately $50 \%$ of all RA associated deaths ${ }^{4}$.

Epicardial adipose tissue (EAT), a type of visceral adipose tissue, is considered to play a pivotal role in the pathogenesis of coronary artery disease (CAD). Recently, several studies have demonstrated that epicardial fat is associated with insulin resistance ${ }^{5}$, increased cardio-metabolic risk ${ }^{6}$, inflammatory markers ${ }^{7,8}$ and coronary artery disease ${ }^{9,10}$. The echocardiographic measurement of EAT, is an objective, noninvasive, readily available, and less expensive measure than magnetic resonance imaging or computed tomography. 
Our aim was to evaluate epicardial fat thickness (EFT) lying in the left lateral position. The measurement and using echocardiography in patients with rheumatoid ar- recordings were carried out as normal inspiratory and thritis compared to healthy control subjects. Secondly, we investigated the relationship between EFT and clinical and echocardiographic parameters in patients with rheumatoid arthritis.

\section{Methods}

Study Population

The study population included 76 consecutive patients with rheumatoid arthritis (64 female; mean age, $53 \pm 11$ years, and median disease duration, 7.8 years) and 50 healthy subjects as controls (39 female; mean age, $52 \pm 6$ years). All patients met the American College of Rheumatology's grading criteria for a diagnosis of $\mathrm{RA}^{11}$. A detailed history and analysis of patients was performed. The inclusion criteria for the study groups were: age $\geq 18$ years, patient's informed consent, absence of any acute disease. Patients with any of the followi tures were excluded from participation: patients with valvular heart disease; chronic obstructive pulmonary disease, any other significant systemic disease, obstructive coronary artery disease, history of heart failure, hepatic failure, hypertension, serum creatinine $>1.4$ $\mathrm{mg} / \mathrm{dL}$, patients with a history of diabetes mellitus (or fasting blood glucose $>125 \mathrm{mg} / \mathrm{dL}$ ), pregnant women, patients with hypo or hyperthyroidism, patients with a BMI $>25 \mathrm{~kg} / \mathrm{m} 2$, and patients who wished to consume alcohol during the study period. Also, we excluded patients with : heart failure, significant valvular heart disease, pacemaker implantation, atrial flutter or fibrillation, frequent ventricular pre-excitation and atrioventricular conduction abnormalities, renal failure, previ ous myocardial infarction, or cerebrovascular accident and poor echocardiographic imaging.

This study was conducted in accordance with the Declaration of Helsinki and was approved by our local ethics committee. Informed consent for the procedure was obtained from each patient.

\section{Echocardiography}

All patients underwent echocardiography. Following a resting period of $15 \mathrm{~min}$, all the patients underwent two-dimensional and Doppler echocardiographic evaluation, including tissue Doppler imaging (TDI) with the echocardiogram device using a $3.5-\mathrm{MHz}$ transducer. Echocardiograms of all patients were recorded as standard parasternal and apical images with the patients end-expiratory. Doppler records of M-mode, pulse and continuous waves were obtained for each case. All the measurements were performed based on the standards of the American Society of Echocardiography by the same cardiologist. Left atrial diameter (LAD), left ventricular end-diastolic diameter (LVEDD), ejection fraction (EF), intraventricular septum thickness (IVS), posterior wall thickness (PW) values were defined from the recordings obtained with the conventional echocardiography. In the pulsed-wave echocardiographic transmittal flow screenings, early diastolic mitral peak velocity $(E)$, late diastolic mitral peak velocity $(A)$, were measured based on the reference images of the apical 4 chamber. On TDI, early diastolic myocardial peak velocity (é) was recorded with apical 4-chamber images using a sampling volume of $5 \mathrm{~mm}$ in the septal and lateral mitral annular regions. All Doppler measurements were carried out manually $\mathrm{E} / \mathrm{A}$, and $\mathrm{E} / \mathrm{e}$.

Epicardial fat thickness was evaluated on the free wall of the right ventricle from the parasternal long-axi view, using the aortic annulus as an anatomic reference. Epicardial fat thickness, identified as an echo-free space between the myocardium and visceral pericardium on two-dimensional echocardiography, was measured perpendicularly, ahead of the right ventricular free wall, at the end of diastole, for three cardiac cycles ${ }^{12}$.

\section{Laboratory}

Blood samples were drawn by venipuncture to measure outine blood chemistry parameters after fasting for at least eight hours. Fasting blood glucose, serum creatinine, total cholesterol, high-density lipoprotein cholesterol, low-density lipoprotein cholesterol, and triglyceride levels were recorded. Glucose, creatinine, and lipid profile were determined using standard methods.

\section{Statistical analysis}

The statistical analyis was performed using software (SPSS 18.0). Parametric values were given as mean \pm standard deviation and non-parametric values were given as a percentage. To compare parametric continuous variables, the Student's t-test was used; to compare nonparametric continuous variables, the Mann-Whitney U-test was used. Categorical data was compared by the Chi-square distribution. Correlation analysis was performed to determine the relationship between epi-

cardial fat tissue and other cardio-metabolic risk factor. Results Two-tailed P-values of less than 0.05 were considered to indicate statistical significance.

\section{Clinical Features}

According to the basic clinical and demographic characteristics, both groups of the study were similar with regard to age, body mass index, fasting glucose, hypertension, diabetes mellitus, and smoking status (table 1).

Table 1: Basal characteristic of patients

\begin{tabular}{|c|c|c|c|}
\hline & $\begin{array}{c}\text { Rheumatoid } \\
\text { arthritis } \\
(\mathrm{n}=76)\end{array}$ & $\begin{array}{l}\text { Healthy controls } \\
\qquad(\mathrm{n}=50)\end{array}$ & P value \\
\hline Age & $53 \pm 11$ & $52 \pm 6$ & 0.430 \\
\hline Gender (Female) & $6484 \%$ & $3978 \%$ & 0.257 \\
\hline Diabetes mellitus, \% & $8 \quad 10 \%$ & $6 \quad 11 \%$ & 0.105 \\
\hline Hypertension, \% & $35 \quad 47 \%$ & $21 \quad 43 \%$ & 0.401 \\
\hline Smoking, \% & $79.2 \%$ & $6 \quad 12.2 \%$ & 0.416 \\
\hline Rheumatoid factor & $23.7(1.0-200)$ & - & \\
\hline Disease duration, years & $7.84(2.4-30)$ & - & \\
\hline Steroid use, $\mathrm{n}$ & $29(38 \%)$ & - & \\
\hline C-reactive protein, mg/dl & $19.2 \pm 46.3$ & $1.7 \pm 3.7$ & 0.007 \\
\hline Body mass Index & $32 \pm 6$ & $34 \pm 8$ & 0.122 \\
\hline Waist circumstance & $101.12 \pm 13.62$ & $103.18 \pm 14.53$ & 0.424 \\
\hline Glucose, mg/dl & $93.18 \pm 16.83$ & $98.7333 \pm 13.26$ & 0.770 \\
\hline Triglyceride, mg/dl & $137.75 \pm 52.29$ & $149.41 \pm 60.99$ & 0.360 \\
\hline High density lipoprotein, mg/dl & $42.87 \pm 6.98$ & $41.81 \pm 7.0$ & 0.494 \\
\hline Total cholesterol, mg/dl & $203.70 \pm 53.70$ & $211.31 \pm 47.38$ & 0.529 \\
\hline Low density lipoprotein, $\mathrm{mg} / \mathrm{dl}$ & $126.62 \pm 34.28$ & $122.16 \pm 33.384$ & 0.553 \\
\hline
\end{tabular}

\section{Echocardiographic data} among rheumatoid arthritis patients and healthy con- matoid arthritis compared to healthy controls. trols are shown in table 2 . Thickness of IVS $(1.1 \pm 0.06$ 
Table 2: Echocardiographic features of patients

\begin{tabular}{|l|c|c|c|}
\hline & $\begin{array}{c}\text { Rheumatoid } \\
\text { arthritis } \\
(\mathbf{n}=\mathbf{7 6})\end{array}$ & $\begin{array}{c}\text { Healthy controls } \\
(\mathbf{n}=\mathbf{5 0 )}\end{array}$ & P value \\
\hline Epicardial fat thickness,cm & $0.66 \pm 0.20$ & $0.54 \pm 0.18$ & $\mathbf{0 . 0 0 3}$ \\
\hline Ejection fraction, \% & $63 \pm 6$ & $62 \pm 4$ & 0.733 \\
\hline LVEDD,cm & $4.5 \pm 0.31$ & $4.4 \pm 0.27$ & 0.536 \\
\hline LAD,cm & $3.43 \pm 0.42$ & $3.46 \pm 0.52$ & 0.647 \\
\hline IVS,cm & $1.1 \pm 0.06$ & $0.98 \pm 0.08$ & $\mathbf{0 . 0 1 0}$ \\
\hline PW, cm & $0.98 \pm 0.05$ & $0.93 \pm 0.08$ & $\mathbf{0 . 0 1 5}$ \\
\hline Diastolic function & $74 \pm 10$ & $86 \pm 12$ & $\mathbf{0 . 0 0 1}$ \\
\hline E cm/s & $76 \pm 14$ & $73 \pm 9$ & $\mathbf{0 . 1 4 0}$ \\
\hline A cm/s & $1.1 \pm 0.8$ & $1.24 \pm 0.1$ & $\mathbf{0 . 0 0 1}$ \\
\hline E/A & $8.6 \pm 1.5$ & $11 \pm 1.6$ & $\mathbf{0 . 0 0 1}$ \\
\hline e' $^{\prime} \mathrm{cm} / \mathrm{s}$ & $8.7 \pm 1.6$ & $8.0 \pm 1.4$ & $\mathbf{0 . 0 2 0}$ \\
\hline E/e'
\end{tabular}

$\mathrm{E}$ wave and $\mathrm{E} / \mathrm{A}$ ratio was lower in rheumatoid arthri- thritis patients compared to healthy controls $(0.66 \pm 0.20$ tis patients compared to healthy patients (E: $74 \pm 10$ vs. $0.54 \pm 0.18$; p:0.003). In patients with rheumatoid and $86 \pm 12 \mathrm{p}=0.01$ vs E/A: $1.1 \pm 0.8$ and $1.24 \pm 0.1$ arthritis, EFT was positively correlated with hyperten$\mathrm{p}=0.001)$ as well as, $\mathrm{E} / \mathrm{e}^{\prime}$ was higher in RA patients than sion and duration of disease and $\mathrm{E} / \mathrm{e}^{\prime}(\mathrm{r}: 0.10 \mathrm{p}: 0.010$

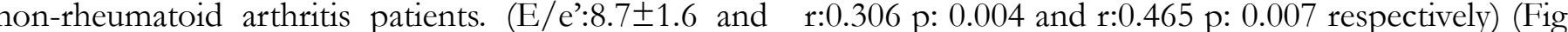
$8.0 \pm 1.4 \mathrm{p}=0.020)$. EFT was higher in rheumatoid ar- ure 1) and EFT was negatively correlated with $\mathrm{e} / \mathrm{a}(\mathrm{r}$ : .262 p:0.022 and) (Figure 2)

Figure 1
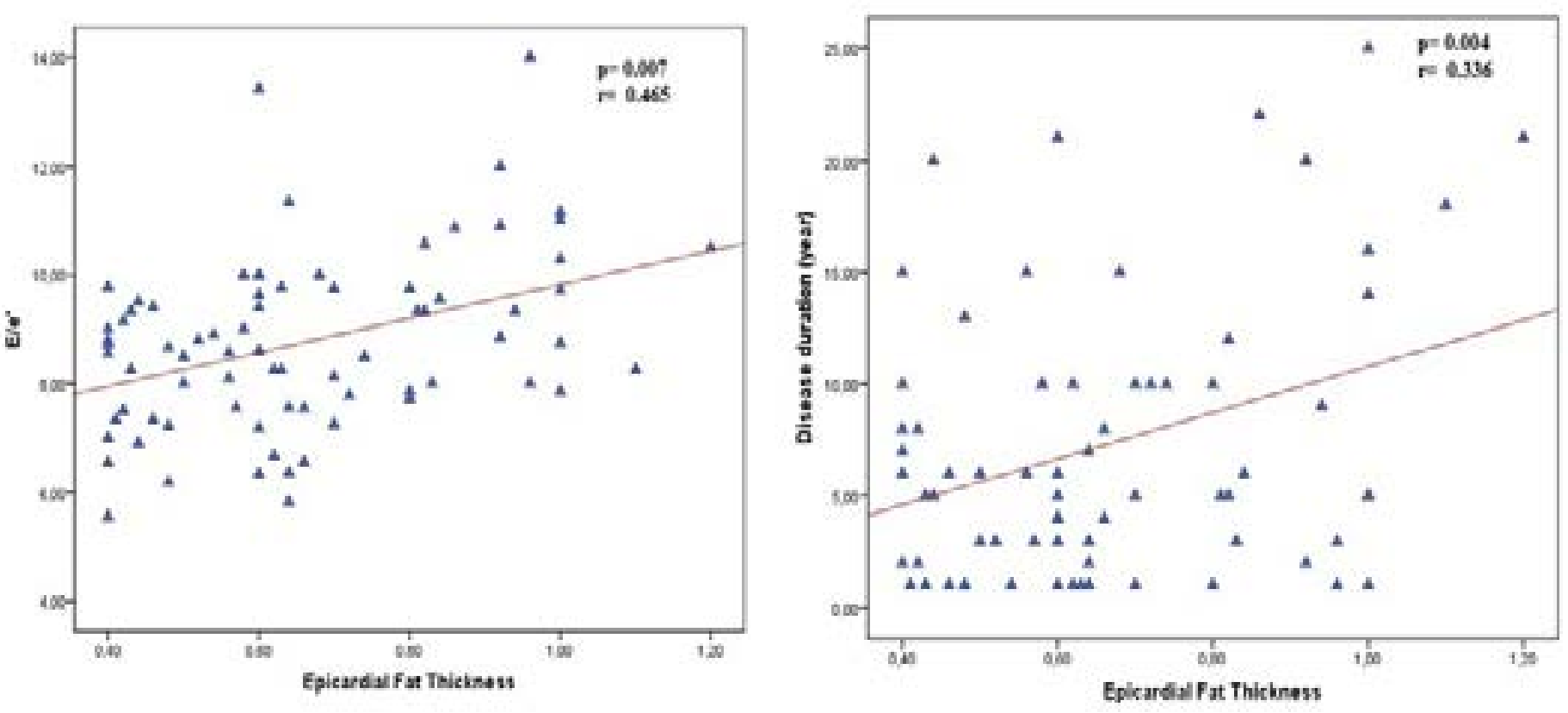

Figure 2

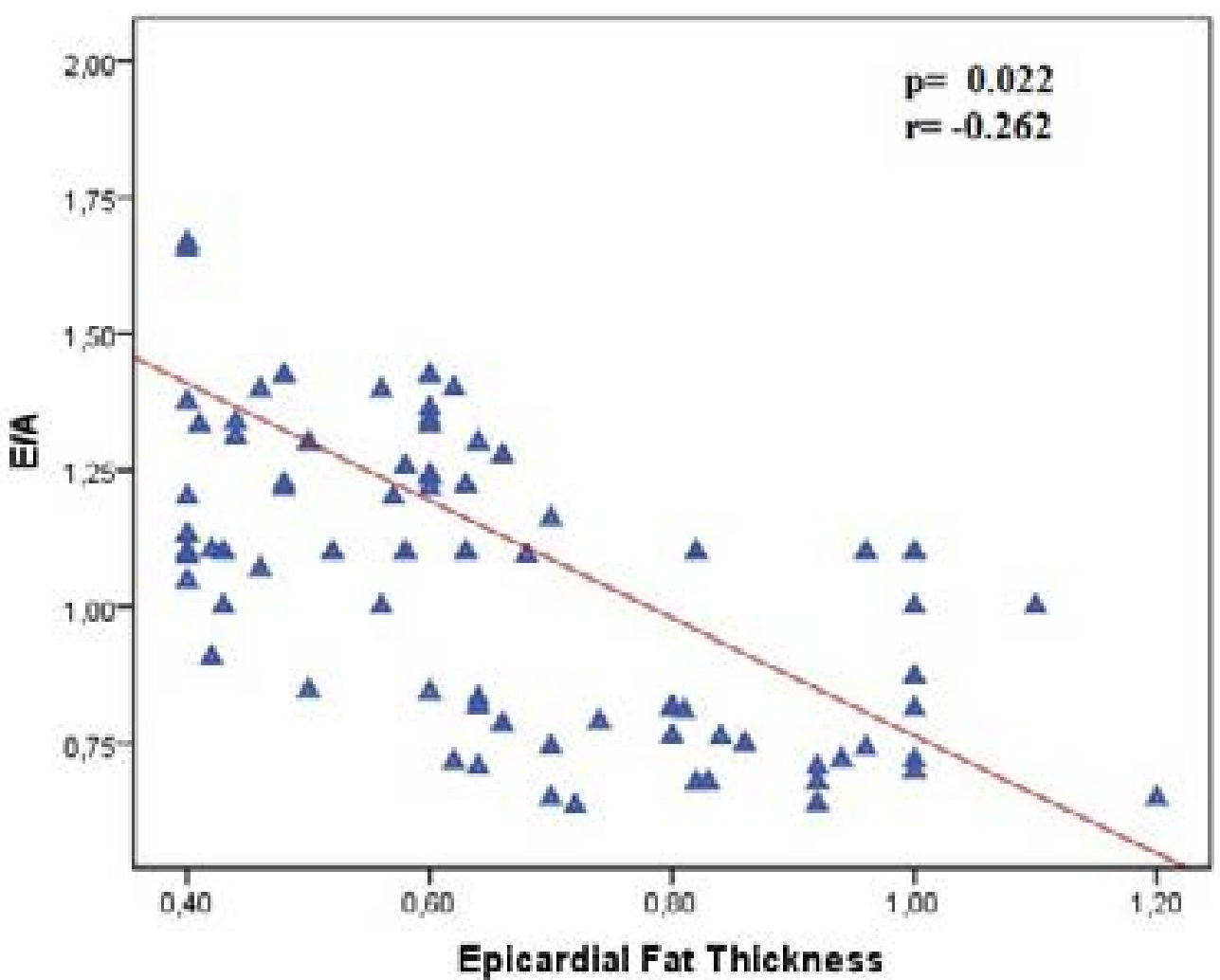

Left ventricular diastolic dysfunction was detected in EAT releases a wide range of biologically active mol$30(39 \%)$ of 75 patients with rheumatoid arthritis; 24 ecules that modulate vascular smooth-muscle contracpatients presented with diastolic dysfunction I and $6 \mathrm{pa}-$ tion. Their paracrine effects might be attributable to tients presented with diastolic dysfunction II.

their location being close to the adventitia and extravascular bed ${ }^{14-16}$ Gastaldelli et al. ${ }^{16}$ reported the existence of a link between EAT and hypertension, atherosclerosis,

\section{Discussion}

In our study, we showed that EFT was higher in pa- and coronary heart disease. Nakanishi and colleagues ${ }^{17}$
tients with rheumatoid arthritis than in the healthy reported that increased epicardial fat volume measured control. Secondly, we demonstrated that left ventricular by CT is associated with greater progression of corwall thickness and diastolic dysfunction were higher and onary artery calcification. Transthoracic echocardiogEFT was well correlated with diastolic dysfunction and raphy provides non-invasive assessment of $\mathrm{EFT}^{6,12}$. disease duration in patients with rheumatoid arthritis. Several studies have emphasized the link between EFT These findings may be associated with cardiovascular and the severity of coronary artery disease (CAD) ${ }^{19-21}$ involvement in patients with rheumatoid arthritis.

Rheumatoid arthritis is linked with an increase in mortality because of stimulation of coronary and cerebrovascular atherosclerosis. ${ }^{13}$ Emerging epidemiological evidence showed that CVDs account for approximatey $50 \%$ of all RA associated deaths ${ }^{4}$. EAT, a type of visceral adipose tissue, is thought to play a pivotal role in the pathogenesis of coronary artery disease (CAD). EFT has an important role in the inflammatory process within the atherosclerotic plaque 9 . In our study, we demonstrated that EFT was higher in patients with rheumatoid arthritis. In addition, we showed that EFT was associated with duration of disease, hypertension, and diastolic dysfunction in patients with rheumatoid arthritis. These findings indicate that rheumatoid arthritis patients may be having an underlying risk of cardiovascular disease. 
Isolated diastolic dysfunction is related to prominent Epicardial fat thickness as an indicator of cardiovascuincrease in all-cause mortality in the general popula- lar involvement was higher in patients with rheumatoid tion $^{22,23}$. Left venticular dibstolic dysfunction (LVDD) is frequently related to common structural abnormalities, such as hypertrophy or interstitial fibrosis, and impaired myocyte relaxation due to ischemia ${ }^{24}$. Previous studies showed the existence of LVDD in patients with RA without clinically prominent cardiac disease..$^{25-27}$. Liang et al. investigated the prevalence of LVDD in patients with RA. They found that patients with RA have a higher prevalence of LVDD than those healthy controls and RA duration is also independently associated with $\mathrm{LVDD}^{28}$. In our study, LVDD was detected in $30(39 \%)$ of 75 patients with rheumatoid arthritis; 24 patients presented with diastolic dysfunction I and 6 patients presented with diastolic dysfunction II. Rudominer et al. showed that left ventricular hypertrophy is higher compared to healthy patients ${ }^{3}$. LV hypertrophy predicts cardiovascular outcomes independent of traditional risk factors ${ }^{30-32}$. In our study, we found that left ventricular wall thickness was increased in patients with rheumatoid arthritis.

The use of the Doppler echocardiography technique to evaluate left ventricular filling by trans-mitral flow is considered a reliable method. ${ }^{2}$ The relation between trans-mitral flow variation and disease duration in theumatoid arthritis indicate a subclinical myocardial involvement. ${ }^{25}$ In our study, we showed that diastolic function in patients with rheumatoid arthritis was impaired compared to those healthy patients. In addition, we demonstrated that disease duration in patients with rheumatoid arthritis was associated with diastolic dysfunction: consistent with previous studies.

\section{Limitations}

Some limitations of this study are evident. The primary limitation of our study was the small sample size. A small sample size has low statistical power and, thus, may yield false-negative results. The other limitation of our study is its cross-sectional design. The results cannot be generalized to the general population. Neither can we apply our results to the general population due to the numerous exclusion criteria. Despite this, we believe that our findings provide a valuable contribution to the EFT and RA. Future prospective much larger multicenter studies are required to confirm our results.

Conclusion arthritis. Also, we showed that diastolic dysfunction and left ventricular hypertrophy were higher in rheumatoid cardiac involvement in patients with RA and those patients may be underlying risk factors for development of cardiovascular disease.

\section{Conflict of Interest: None}

\section{References}

1. Gabriel SE. The epidemiology of rheumatoid arthritis. Rheum Dis Clin North Am. 2001; 27 (2):269-81.

2. Meune C, Touze E, Trinquart L, Allanore Y. Trends in cardiovascular mortality in patients with rheumatoid arthritis over 50 years: a systematic review and mea-analysis of cohort studies. Rheumatology 2009; 48 (10):1309-13.

3. Avina-Zubieta JA, Choi HK, Sadatsafavi M, Etminan M, Esdaile JM, Lacaille D. Risk of cardiovascular morysis of observational studies. Arthritis Rheum. 2008; 59 (12):1690 PubMed -7.

4. Yazmalar L, Ediz L, Alpayci M, Hiz O, Toprak M, D levels in rheumatoid arthritis, ankylosing spondylitis and osteoarthritis. Afr Health Sci. 2013 Mar;13(1):47-55. 5. Cengel A. Epicardial adipose tissue, metabolic syndrome, inflammation, and cardiovascular risk. Turk Kardiyol Dern Ars. 2012 Dec;40(8):696-8.

6. Iacobellis G, Ribaudo MC, Assael F, Vecci E, Tiberti C, Zappaterreno A, et al. Echocardiographic epicardial adipose tissue is related to anthropometric and clinical parameters of metabolic syndrome: a new indicator of cardiovascular risk. J Clin Endocrinol Metab. 2003; 88 (11):5163-8.

7. Malavazos AE, Ermetici F, Cereda E, Coman C, Locati M, Morricone L, et al. Epicardial fat thickness: relationship with plasma visfatin and plasminogen activato inhibitor-1 levels in visceral obesity. Nutr Metab Cardiovasc Dis. 2008; 18 (8):523-30.

8. Kremen J, Dolinkova M, Krajickova J, Blaha J, Anderlova K, Lacinova Z, et al. Increased subcutaneous and epicardial adipose tissue production of proinflammatory cytokines in cardiac surgery patients: possible role in postoperative insulin resistance. J Clin Endocrinol Metab. 2006; 91 (11):4620-7.

9. Şengül C, Özveren O. Epicardial adipose tissue: a review of physiology, pathophysiology, and clinical appliarthritis patients. These findings suggest that subclinical tality in patients with rheumatoid arthritis: a meta-analTekeoglu I. Seasonal disease activity and serum vitamin cations. Anadolu Kardiyol Derg. 2013 May;13(3):261-5. 10. Iacobellis G, Lonn E, Lamy A, Singh N, Sharma AM. Epicardial fat thickness and coronary artery disease correlate independently of obesity. Int J Cardiol. 2011; 146 (3):452 PubMed -4.

11. Arnett FC, Edworthy SM, Bloch DA, McShane DJ, Fries JF, Cooper NS, et al. The American Rheumatism Association 1987 revised criteria for the classification of rheumatoid arthritis. Arthritis Rheum. 1988; 31 (3):315 PubMed -24.

12. Iacobellis G, Assael F, Ribaudo MC, Zappaterren A, Alessi G, Di Mario U, et al. Epicardial fat from echocardiography: a new method for visceral adipose tissue prediction. Obes Res. 2003; 11 (2):304 PubMed -10.

13. Kaplan MJ. Cardiovascular disease in rheumatoid arthritis. Curr Opin Rheumatol. 2006;18 (3):289 PubMed $-97$.

14. Szasz T, Webb RC. Perivascular adipose tissue: more than just structural support. Clin Sci (Lond). 2012; $122(1): 1-12$.

15. Bachar GN, Dicker D, Kornowski R, Atar E. Epicardial adipose tissue as a predictor of coronary artery disease in asymptomatic subjects. Am J Cardiol. 2012; 110 (4):534 PubMed -8.

16. Gastaldelli A, Basta G. Ectopic fat and cardiovascular disease: what is the link? Nutr Metab Cardiovasc Dis 2010; 20 (7):481-90.

17. Nakanishi R, Rajani R, Cheng VY, Gransar $\mathrm{H}, \mathrm{Na}-$ kazato R, Shmilovich H, et al. Increase in epicardial fat volume is associated with greater coronary artery calcification progression in subjects at intermediate risk by coronary calcium score: a serial study using non-contrast cardiac CT. Atherosclerosis. 2011; 218 (2):363 PubMed -8 .

18. Baker AR, Silva NF, Quinn DW, Harte AL, Pagano
, Bonser RS, et al. Human epicardial adipose tissue expresses a pathogenic profile of adipocytokines in patients with cardiovascular disease. Cardiovasc Diabetol. 2006; 5:1.

19. ChaowalitN, Somers VK, Pellikka PA, Rihal CS, Lopez-Jimenez F. Subepicardial adipose tissue and the presence and severity of coronary artery disease. Atherosclerosis. 2006; 186 (2):354 PubMed -9.

20. Jeong JW, Jeong MH, Yun KH, Oh SK, Park EM, Kim YK, et al. Echocardiographic epicardial fat thickness and coronary artery disease. Circ J. 2007; 71 (4):536 PubMed -9.

21. Ahn SG, Lim HS, Joe DY, Kang SJ, Choi BJ, Choi SY, et al. Relationship of epicardial adipose tissue by echocardiography to coronary artery disease. Heart. 2008; 94 (3): PubMed e7.

22. Redfield MM, Jacobsen SJ, Burnett JC, Jr., Mahoney DW, Bailey KR, Rodeheffer RJ. Burden of systolic and diastolic ventricular dysfunction in the community: appreciating the scope of the heart failure epidemic. JAMA. 2003; 289 (2):194 PubMed -202.

23. Bursi F, Weston SA, Redfield MM, Jacobsen SJ, Pakhomov S, Nkomo VT, et al. Systolic and diastolic heart failure in the community. JAMA. 2006; 296 (18):2209 PubMed -16 .

24. Udayakumar N, Venkatesan S, Rajendiran C. Diastolic function abnormalities in rheumatoid arthritis: reation with duration of disease. Singapore Med J. 2007; 48 (6):537 PubMed -42.

25. Di Franco M, Paradiso M, Mammarella A, Paoletti V, Labbadia G, Coppotelli L, et al. Diastolic function abnormalities in rheumatoid arthritis. Evaluation By echo Doppler transmitral flow and pulmonary venous flow: relation with duration of disease. Ann Rheum Dis. 2000; 59 (3):227 